\title{
Waves and climate change in the north-east Atlantic
}

\author{
Judith Wolf ${ }^{1}$ and David K. Woolf ${ }^{2}$ \\ Received 2 November 2005; revised 2 February 2006; accepted 6 February 2006; published 18 March 2006.
}

[1] Wave height in the North Atlantic has been observed to increase over the last quarter-century, based on monthlymean data derived from observations. Empirical models have linked a large part of this increase in wave height with the North Atlantic Oscillation. Wave models provide a tool to study impacts of various climate change scenarios and investigate physical explanations of statistical results. In this case we use a wave model of the NE Atlantic. Model tests were carried out, using synthetic wind fields, varying the strength of the prevailing westerly winds and the frequency and intensity of storms, the location of storm tracks and the storm propagation speed. The strength of the westerly winds is most effective at increasing mean and maximum monthly wave height. The frequency, intensity, track and speed of storms have little effect on the mean wave height but intensity, track and speed significantly affect maximum wave height. Citation: Wolf, J., and D. K. Woolf (2006), Waves and climate change in the north-east Atlantic, Geophys. Res. Lett., 33, L06604, doi:10.1029/2005GL025113.

\section{Introduction}

[2] Wave height in the North Atlantic, as observed from in-situ and altimeter observations, has increased over the last quarter-century [Carter, 1999]. Woolf et al. [2002] related North Atlantic wave height to the North Atlantic Oscillation (NAO), a measure of the North Atlantic meridional air pressure gradient and the strength of the prevailing westerly winds, producing a predictive model. The positive phase of the NAO corresponds to stronger westerly winds. Prediction of future changes in wave height requires understanding the role of such decadal oscillations and their likely future evolution, as well as other potential climate change mechanisms. In particular we need to understand the mechanism behind the recent increase in wave heights.

[3] Observational wave data from buoys, ships and satellite altimetry provide a statistical basis for analysing variability but cannot elucidate cause and effect on their own. Wave models, once validated, offer the capability of interpreting, interpolating and extrapolating the available observations.

[4] We use a North East Atlantic (NEA) wave model [Wolf et al., 2002; Wolf and Woolf, 2005] to investigate the effects of idealised storm conditions, changing the intensity and frequency of storms and the strength of the background westerly wind field. First we examine the role of storminess, its variability in the historical record and its prediction in climate models. Then we present the wave model, its setup

\footnotetext{
${ }^{1}$ Proudman Oceanographic Laboratory, Liverpool, UK.

${ }^{2}$ National Oceanography Centre, Southampton, UK.

Copyright 2006 by the American Geophysical Union. 0094-8276/06/2005GL025113\$05.00
}

and validation and the experiments with synthetic wind fields, followed by results and a discussion of the implications for the future.

\section{2. 'Storminess' in Climate Models and the Historical Record}

[5] Two possible explanations for the increase in wave height with NAO are (a) an increase in the mean zonal wind, increasing the build-up of waves over several days or (b) an increase in 'storminess' i.e., the frequency and intensity of storms [Woolf et al., 2002]. Here we are interested in mid-latitude baroclinic systems rather than tropical warm-core hurricanes.

[6] Studies of changes in storminess over previous centuries, for example, from windblown sand deposits in the Outer Hebrides [Dawson et al., 2004] suggest the most significant episodes of windstorm deposition pre-date and postdate the Medieval Warm Period (ending in about 1400. These may be associated with changes in Icelandic sea ice extent [Meeker and Mayewski, 2002]. Lamb [1991] discusses storms over the North Sea, British Isles and Europe going back over the last 500 years, the earlier records mostly resulting from associated coastal flooding. Storminess appears to have varied over decadal and century timescales. Mean sea level fell during the Little Ice Age (16th to 19th century) apparently coincidental with more frequent storms.

[7] There have been significant increases in the number of severe storms over the UK since the 1950s [Alexander et al., 2005], which appear to be related to changes in the NAO to a more positive phase. It remains uncertain whether the multi-decadal NAO variability is related to climate change [Tsimplis et al., 2005]. Distinguishing natural from anthropogenic variability from observations is difficult. Climate models suggest an increase in NAO with increased greenhouse gases but the recent observed increase is beyond the range of the model predictions [Kuzmina et al., 2005].

[8] There is a common assumption that global warming may lead to increased storminess (http://meteo.pr.erau.edu/ sinclair_cyclones_and_global_warming.php). However the evidence is somewhat contradictory. Sinclair and Watterson [1999] used the CSIRO General Circulation Model (GCM) of the atmosphere to examine changes in the frequency and strength of mid-latitude storms under a doubled $\mathrm{CO}_{2}$ scenario. The polar regions were found to warm more than the tropics, reducing the equator to pole temperature difference. Reducing this gradient results in fewer and weaker storms, but there is some evidence of increased winter cyclone activity near the downstream end of the principal storm tracks.

[9] Chang et al. [2002] provided a useful review of storm track dynamics and found storm tracks exhibit notable variation in intensity on decadal time-scales. It remains to 


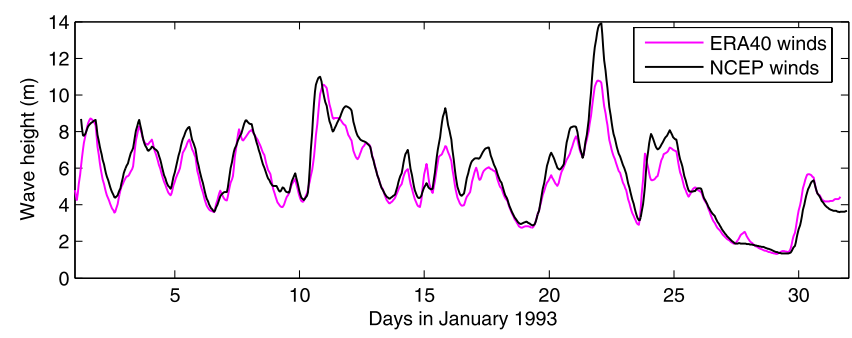

Figure 1. Wave heights implied by ERA-40 versus NCEP reanalysis winds near South Uist for January 1993.

establish a causal relationship between temporal variability of storm track eddies and that of the background flow. Storm track predictability is investigated by Compo and Sardeshmukh [2004]. They find a predictable SST-forced storm track signal exists in many winters, but its strength and pattern can change substantially from winter to winter.

[10] Yin [2005] found a consistent poleward and upward shift and intensification of storm tracks in an ensemble of 21 st century climate simulations using 15 coupled climate models. He refers to recent results observed in reanalysisbased studies showing that there has been a poleward shift in the mean latitude of extratropical storms and cyclones have been fewer but more intense in the latter half of the 20 th century but it is difficult to attribute this to greenhouse gas effects as yet.

\section{Wave Models}

[11] The wave model setup was described by Wolf et al. [2002] and Wolf and Woolf [2005]. The PRO-WAM model [Monbaliu et al., 2000] was set up on a $1^{\circ} \mathrm{NE}$ Atlantic grid. The NEA model extends from $40^{\circ}$ to $70^{\circ} \mathrm{N}$ and $25^{\circ} \mathrm{W}$ to $15^{\circ} \mathrm{E}$. We examine the output at a station west of South Uist in the Outer Hebrides, at $57^{\circ} \mathrm{N}, 8^{\circ} \mathrm{W}$. An extended model covering the whole North Atlantic was tested to avoid omitting any swell energy in boundary conditions for the limited area models but this was found to make less than $5 \%$ difference in the significant wave height for the Hebrides area, in strong wind events [Wolf and Woolf, 2005]. The most intense weather systems are concentrated in the NE Atlantic, so most of the wave generation is captured,

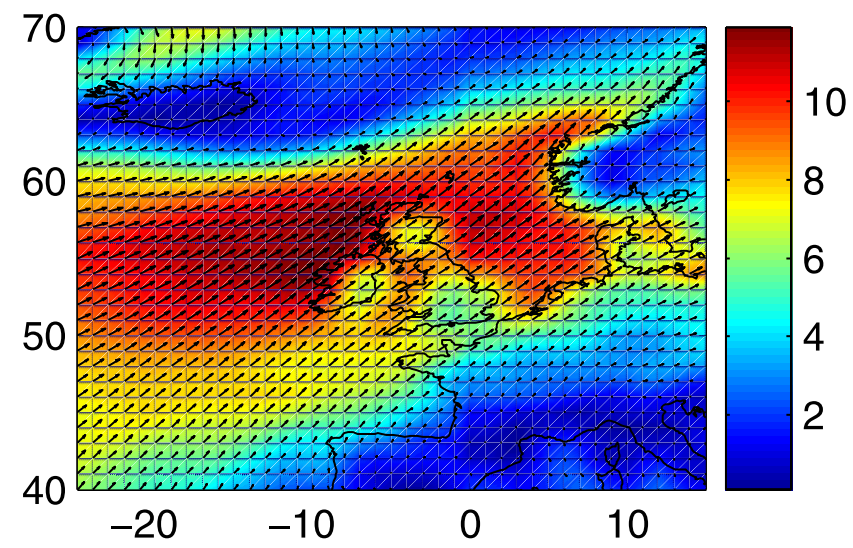

Figure 2. Mean atmospheric conditions for January 1993. Coloured shading/contours is wind speed in $\mathrm{m} / \mathrm{s}$, arrows indicate direction of flow. although there may be some occasions where very long swell travels from the western Atlantic

[12] The wind forcing for the NEA model was derived from the ECMWF ERA-40 reanalysis $\sim 1.5^{\circ}$ resolution global model output at 6-hourly time intervals. Altimeter and buoy data were used to validate the models. The buoys at RARH and K4 provided wave height and period near the shelf edge and 3 buoys near South Uist (wave height only) were used. TOPEX/Poseidon wave heights along tracks 189 and 44 were most useful as they penetrate into the Sea of the Hebrides. Particularly large waves were observed in January 1993 (exceeding 14m on 21 January). Model simulations were carried out for 11, 17 and 21 January to coincide with altimeter passes. Detailed results of the validation are given in Wolf and Woolf [2005]. The model somewhat underestimates the peak wave height in storm events at K4. However it can be demonstrated that the ERA-40 winds are underestimated compared to NCEP/NCAR re-analysis winds (http://www.cdc.noaa.gov/cdc/reanalysis/reanalysis.shtml) at $2.5^{\circ}$ resolution and this leads to generally reduced wave height (Figure 1). Both these models have rather coarse spatial resolution, which precludes good resolution of the most extreme and intense storm events. Caires and Sterl [2003] show that ERA-40 predictions underestimate high values of significant wave height. Bauer and Weisse [2000] show that adding statistical wind variability can increase wave height predictions.

[13] There is still some uncertainty in the altimeter calibration at very high wind speeds (due to lack of data) but comparison of altimeter wave heights with the K4 buoy during January 1993 validates the altimeter data. Improvement is needed in the atmospheric models used to force the wave model, such as the use of higher spatial resolution.

[14] Agreement between model and observations was reasonable (the pattern of observed wave events was reproduced) with discrepancies attributable to the coarse spatial and temporal resolution of the wind data. Therefore the wave model was considered satisfactory and applied to the present study using idealised wind fields.

\section{Idealised Storm Modelling}

[15] The ERA-40 winds for January 1993 were taken as the basis for a sensitivity study, since this is prototypical of a positive NAO month. A sequence of depressions passes through the area from SW to NE during the month. The

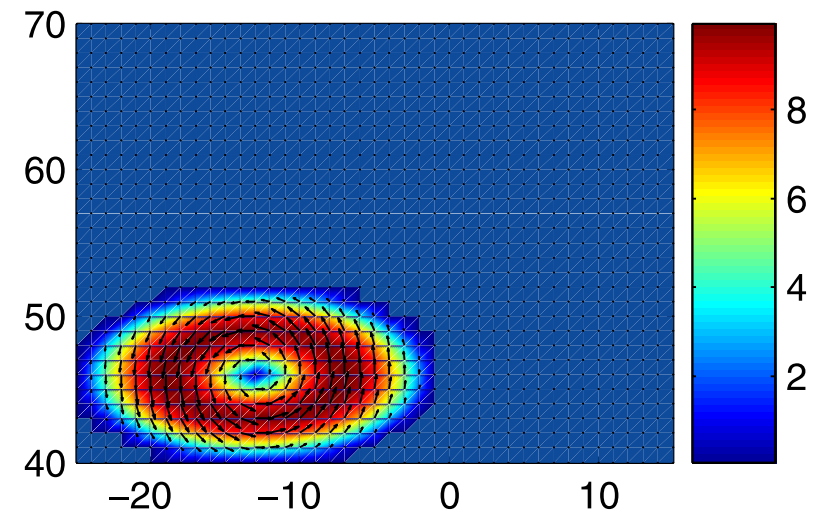

Figure 3. Idealised storm with maximum wind speed $10 \mathrm{~m} / \mathrm{s}$. 
Table 1. Features of the Storm Varied in the Experiments ${ }^{\mathrm{a}}$

\begin{tabular}{llll}
\hline \multicolumn{1}{c}{ Feature } & Low & Med & High \\
\hline Frequency $\left(\mathrm{month}^{-1}\right)$ & 3 & $\mathbf{6}$ & 9 \\
Intensity $\left(\mathrm{m} \mathrm{s}^{-1}\right)$ & 10 & 15 & $\mathbf{2 0}$ \\
Relative Strength & 0.5 & $\mathbf{1}$ & 1.5 \\
Direction & ENE & $\mathbf{N E}$ & NNE \\
Speed $\left(\mathrm{km} \mathrm{h}^{-1}\right)$ & 25 & $\mathbf{5 0}$ & 100 \\
\hline
\end{tabular}

"Values in bold are the "standard" case.

vector average wind field for the month is shown in Figure 2, in which the prevailing westerly winds can be seen. This field was taken as the background wind field, which was multiplied by a constant factor $(0.5,1$ or 1.5$)$ to represent different intensities of the westerly winds. On top of this was superimposed a sequence of 'idealised' storms, as in Figure 3, with a fixed radius to maximum winds of $333 \mathrm{~km}$ and varying intensity and frequency.

[16] The standard case consisted of the original background wind field and a frequency of 6 storms per month with an intensity of $20 \mathrm{~m} / \mathrm{s}$ (maximum wind speed) translating to the NE with a translation speed of $50 \mathrm{~km} / \mathrm{h}$. The relative strength of the background field and 4 properties of the storms were varied as summarised in Table 1. Although some of these variables may be inter-related in real storms, this simple model allows separation of their effects.

[17] Several months of synthetic winds were generated, which were used to force the wave model, from which the mean and maximum wave heights for each month were derived.

\section{Results}

[18] The sensitivity of the wave height at a point west of the Hebrides $\left(57^{\circ} \mathrm{N}, 8^{\circ} \mathrm{W}\right)$, to each single variable, is plotted in Figure 4.

[19] Mean monthly wave heights are most sensitive to the relative strength of the westerlies. The maximum wave height is fairly sensitive to all variables except for the frequency of storms. The largest waves are associated with a strong background field and intense storms translating slowly on a relatively northerly track. Typically the waves grow most in the SE quadrant of the storm where the wind speed is in the same direction as the storm is moving.

[20] Mean wave direction (generally from SW) is not sensitive to these variables except in the case of weak westerlies with the most intense storms, when the mean wave direction becomes more zonal. The actual wave direction time series is then dominated by the periodic variation of wave direction from SW to NW associated with the passage of each storm event.

\section{Discussion}

[21] The importance of the background wind field and the storm translation speed can be explained by the importance of dynamic fetch, in which the effective wind input is increased if the storm moves at about the same speed as the waves (wave height increases with wind speed, fetch and duration). Waves can also reach their fully-developed state in a steady wind. Typical storm translation speeds are larger than the group velocity of all but the longest waves, which explains why in our experiments the slowest speed resulted in the highest waves. At normal translation speeds the storm outruns the waves. This tendency is increased for accelerated storm passages, as also found in simulations by Bauer et al. [1996].

[22] The recent increase in wave height is highly correlated $(>0.8)$ with an increase in the positive phase of the NAO [Woolf et al., 2002] for a large area west of the Hebrides. Wang et al. [2004] assume the relationship will continue to hold and suggest the occurrence of the positive phase of the NAO will be more frequent under global warming. A recent study by Terray et al. [2004] supports this view and indeed suggests that the main change in wintertime weather patterns will be a greatly increased occupancy of the NAO positive pattern at the expense of the occurrence of the NAO negative pattern.

[23] On the other hand, Jones et al. [2003] show that the influence of the NAO has varied significantly over the last $150-200$ years and has been particularly strong recently. The availability of satellite measurements of waves over the last quarter century coincides with a particular phase of the NAO. It is still not clear how important the NAO will be in the future and how much it is linked with climate change [Tsimplis et al., 2005]. In the absence of any other evidence to date their future wave height scenarios are based on predictions of the NAO alone.

[24] Changes in sea ice extent could have an important impact on waves, in changing the fetch over which the wind is blowing. Recently Arctic sea ice has been reducing [e.g., Rigor and Wallace, 2004] and this can have large implications in climate models and on the ocean thermohaline circulation as well as waves.

\section{Conclusions}

[25] A wave model for the NE Atlantic has been used to examine the sensitivity of the sea state to variation in

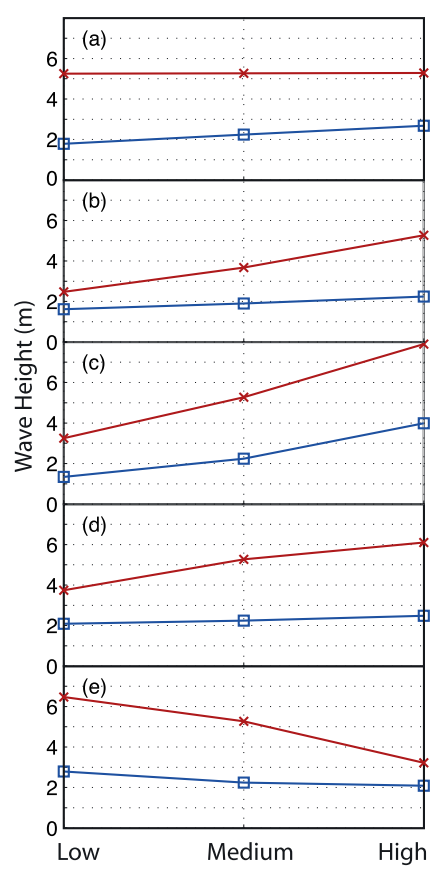

Figure 4. Effect of (a) storm frequency (b) storm intensity (c) relative strength of westerlies (d) storm track and (e) storm translation speed on wave height. Red crosses = monthly maximum, blue squares $=$ monthly mean. 
parameters describing the relative importance of the mean wind speed and the characteristics of storm events. The intensity, frequency, track and speed of storms has less effect on the monthly mean and maximum wave height than the strength of the westerlies. This suggests the recent observed increase in wave height is more likely caused by an intensification of the background westerly atmospheric circulation than by a change in storminess.

[26] Whether wave heights will continue to increase is a question which remains to be answered. The incidence of storms and the strength of the westerly flow are interrelated in ways that need more work to elucidate. The consensus of climate models' predictions for the NAO suggest it is likely to continue in its positive phase which means that wave heights are likely to continue to be larger than those observed in the mid- $20^{\text {th }}$ century. Further work is needed to fully understand the mechanisms controlling the NAO and its role in climate change. Our results provide evidence of the need for climate change scenario simulations and will help to interpret these more complex model simulations.

[27] Acknowledgments. The work described here was (partly) supported by the Tyndall Centre for Climate Research Project "Towards a vulnerability assessment of the UK coast" [Tsimplis et al., 2005]. Model winds were obtained from the ECMWF ERA-40 reanalysis and NCAR/ NCEP reanalysis.

\section{References}

Alexander, L. V., S. F. B. Tett, and T. Jonsson (2005), Recent observed changes in severe storms over the United Kingdom and Iceland, Geophys. Res. Lett., 32, L13704, doi:10.1029/2005GL022371.

Bauer, E., and R. Weisse (2000), Determination of high-frequency wind variability from observations and application to North Atlantic wave modeling, J. Geophys. Res., 105(C11), 26,179-26,190.

Bauer, E., M. Stolley, and H. von Storch (1996), On the response of surface waves to accelerating the wind forcing, Manuscr. 96/E/89, 21 pp., GKSS Res. Cent., Geesthacht, Germany.

Caires, S., and A. Sterl (2003), Validation of ocean wind and wave data using triple collocation, J. Geophys. Res., 108(C3), 3098, doi:10.1029/ 2002JC001491.

Carter, D. J. T. (1999), Variability and trends in the wave climate of the North Atlantic: A review, paper presented at 9th ISOPE Conference, Int. Soc. of Offshore and Polar Eng., Cupertino, Calif.

Chang, E. K. M., S. Lee, and K. L. Swanson (2002), Storm track dynamics, J. Clim., 15, 2163-2183.

Compo, G. P., and P. D. Sardeshmukh (2004), Storm Track predictability on seasonal and decadal scales, J. Clim., 17, 3701-3720.
Dawson, S., D. E. Smith, J. Jordan, and A. G. Dawson (2004), Late Holocene coastal sand movements in the Outer Hebrides, N.W. Scotland, Mar. Geol., 210, 281-306.

Jones, P. D., T. J. Osborn, and K. R. Briffa (2003), Pressure-based measurements of the North Atlantic Oscillation (NAO): A comparison and an assessment of changes in the strength of the NAO and in its influence on surface climate parameters, in The North Atlantic Oscillation: Climatic Significance and Environmental Impact, Geophys. Monogr. Ser., vol. 134, edited by J. W. Hurrell et al., pp. 51-62, AGU, Washington, D. C.

Kuzmina, S. I., L. Bengtsson, O. M. Johannessen, H. Drange, L. P. Bobylev, and M. W. Miles (2005), The North Atlantic Oscillation and greenhouse-gas forcing, Geophys. Res. Lett., 32, L04703, doi:10.1029/2004GL021064.

Lamb, H. H. (1991), Historic Storms of the North Sea, British Isles and Northwest Europe, 204 pp., Cambridge Univ. Press, New York.

Meeker, L. D., and P. A. Mayewski (2002), A 1400-year high-resolution record of atmospheric circulation over the North Atlantic and Asia, Holocene, 12, 257-266.

Monbaliu, J., R. Padilla-Hernandes, J. C. Hargreaves, J.-C. Carretero, W. Luo, M. Sclavo, and H. Gunther (2000), The spectral wave model, WAM, adapted for applications with high spatial resolution, Coastal Eng., 41(1-3), 41-62.

Rigor, I. G., and J. M. Wallace (2004), Variations in the age of Arctic seaice and summer sea-ice extent, Geophys. Res. Lett., 31, L09401, doi:10.1029/2004GL019492.

Sinclair, M. R., and I. G. Watterson (1999), Objective assessment of extratropical weather systems in simulated climates, J. Clim., 12, 3467-3485.

Terray, L., M.-E. Demory, M. Déqué, G. de Coetlogon, and E. Maisonnave (2004), Simulation of late-twenty-first-century changes in wintertime atmospheric circulation over Europe due to anthropogenic causes, J. Clim., 17, 4630-4635.

Tsimplis, M. N., et al. (2005), Towards a vulnerability assessment of the UK and northern European coasts: The role of regional climate variability, Philos. Trans. R. Soc., Ser. A, 363, 1329-1358.

Wang, X. L., F. W. Zwiers, and V. R. Swail (2004), North Atlantic Ocean wave climate change scenarios for the twenty-first century, J. Clim., 17, $2368-2383$.

Wolf, J., and D. K. Woolf (2005), Waves and climate change in the sea of the Hebrides, paper presented at 15th (2005) ISOPE Conference, Int. Soc. of Offshore and Polar Eng., Seoul.

Wolf, J., S. L. Wakelin, and R. A. Flather (2002), Effects of climate change on wave height at the coast, paper presented at Twelfth (2002) ISOPE Conference, Int. Soc. of Offshore and Polar Eng., Kitakyushu, Japan.

Woolf, D. K., P. G. Challenor, and P. D. Cotton (2002), Variability and predictability of the North Atlantic wave climate, J. Geophys. Res., 107(C10), 3145, doi:10.1029/2001JC001124.

Yin, J. H. (2005), A consistent poleward shift of the storm tracks in simulations of 21 st century climate, Geophys. Res. Lett., 32, L18701, doi:10.1029/2005GL023684.

J. Wolf, Proudman Oceanographic Laboratory, 6 Brownlow Street, Liverpool L3 5DA, UK. (jaw@pol.ac.uk)

D. K. Woolf, National Oceanography Centre, Southampton, UK. 